\title{
Microstructure investigation on the fusion zone of steel/nickel-alloy dissimilar weld joint for nozzle buttering in nuclear power industry
}

\author{
X. Guo ${ }^{1,2} \cdot$ P. $\mathrm{He}^{1} \cdot \mathrm{K} . \mathrm{Xu}^{2} \cdot \mathrm{X} . \mathrm{Ch} . \mathrm{Lv}^{2} \cdot$ J. B. Zhang ${ }^{3} \cdot \mathrm{Y} . \mathrm{Gu}^{3}$
}

Received: 18 August 2021 / Accepted: 3 October 2021 / Published online: 9 October 2021

(c) The Author(s) 2021

\begin{abstract}
Microstructure of the fusion zone of steel/nickel-alloy dissimilar metal welds (DMWs) for nozzle buttering was investigated by optical microscopy (OM), scanning electron microscopy (SEM), energy-dispersive spectroscopy (EDS), and electron back-scattered microscopy (EBSD). The results showed that the dissimilar joint was complete, without welding defects. The structures of the fusion zone included the beach structure along the fusion boundary, the peninsula structures connected with the fusion boundary, and the island structures in the weld. The distribution of these three types of structures near the fusion boundary was uneven. The beach structure was formed because of the insufficient mixing and solidification of the molten liquid base material and the filler metal, with the width ranging between 0 and $150 \mu \mathrm{m}$. The peninsula and island structures were formed by the undercooling of the insufficiently mixed liquid base material and filler metal that entered the weld because of the convection and scouring of the weld pool. The composition of the three structures depended on the degree of mixing of the liquid base material and the filler metal, with a dilution ratio between 40 and $60 \%$. The degree of dilution for the beach, peninsula, and island structures decreased in turn. With an increase in the dilution ratio, the initial solidification temperature of the corresponding composition increased significantly. When the dilution ratio exceeded $94.5 \%$, the initial solidification phase transformed from the face-centered cubic $\gamma$-austenite into a body-centered cubic ferrite, with island structures solidified in the form of ferrites in the weld near the fusion boundary. The austenite grain orientations at weld side are dispersed with $75 \%$ large $\left(>15^{\circ}\right)$ misorientation in frequency and the overall texture orientation distributes dispersedly with deviating from the $<100>$ direction.
\end{abstract}

Keywords Dissimilar steel joint $\cdot$ Dilution ratio $\cdot$ Fusion boundary $\cdot$ Buttering layer weld overlay

\section{Introduction}

As a clean, economical, and efficient energy source, nuclear power has received significant attention from around the world. China has become the country with the largest number of nuclear power plants under construction in the world, most of which are pressurized water reactors. DMWs are

Recommended for publication by Commission II-Arc Welding and Filler Metals

X. Guo

guoxiaogarden@163.com

1 State Key Laboratory of Advanced Welding and Joining, Harbin Institute of Technology, Harbin 150001, China

2 Harbin Welding Institute Co., Ltd, 150028 Harbin, China

3 Shanghai Nuclear Engineering Research \& Design Institute Co., Ltd, Shanghai 200233, China prone to failure in the primary water loop because of their unique material characteristics $[1,2]$. The primary damage and failures are manifested as stress corrosion cracking, corrosion cracking, hot cracking, and fusion defects. The formation of these defects is related to various factors, such as the difference in mechanical performance along the weld joint; the difference in thermal expansion coefficients of different materials; and the difference in alloy elements, welding residual stress, carbon migration, and the working environment [3-6].

Due to metallurgical advantages and being able to provide a gradation of coefficient of thermal expansion (CTE) across the weld joint that better distributes stresses resulting from CTE differences at elevated temperatures [7], nickel alloy welding consumables were often applied as buttering layers by shielded metal arc welding (SMAW) and gas tungsten arc welding (GTAW) processes on low alloy steel (LAS) in nuclear power industry, for example buttering layers for LAS 
reactor pressure vessel nozzle and stainless steel (SS) safe end DMWs, LAS reactor pressure vessel head and nickel alloy control rod drive mechanism DMWs. Results demonstrated that ferritic-to austenitic DMWs made with $625 \mathrm{Ni}$ based filler metals exhibited steeper concentration gradient in partially melted zone (PMZ) compared to 309L Fe-based austenitic alloys, which stabilizes the austenite at a relatively short distance [8]. Overlay DMWs with 625 nickel alloy filler metal have been reported to investigate the weldability, segregation, and microstructure [1,9-12].

The ERNiCrFe-13 nickel-based alloy welding wire was developed based on the ERNiCrFe-7A welding wire alloy system by further increasing the niobium content and adding molybdenum to improve the resistance to ductility dip cracking. The resistance to ductility dip cracking of the deposited metal of the ERNiCrFe-13 nickel-based alloy welding wire has been dramatically improved, with the critical noncracking strain $\varepsilon_{\min }$ roughly as high as $10 \%$ [13]. Thus far, studies on $\mathrm{ERNiCrFe}-13$ welding wire mainly have focused on the structure, performance, and weldability of the weld $[14,15]$. The application of the welding wire on the dissimilar steel joint has not yet been investigated.

In this study, by tentatively producing ERNiCrFe-13 welding wire, we investigated the DMW fusion zone microstructure of the SA508 Gr.3 Cl.2/ERNiCrFe-13 from buttering layer weld overlay of the nuclear reactor safety end. We also analyzed the formation mechanisms of the beach, peninsula, and island structures. The results provide experimental support for the evaluation of the welding process and the key monitoring parts in the actual operation of nuclear power plants.

\section{Test materials and methods}

The base material was SA508 Gr.3 Cl.2 forging with the specifications of $\Phi 510 \mathrm{~mm}$ (inner diameter) $\times 80 \mathrm{~mm}$ (thickness) $\times 150 \mathrm{~mm}$ (width). The filler metal used for the test was experimental ERNiCrFe-13 nickel-based alloy filler metal, with the specification of $\Phi 1.2 \mathrm{~mm}$. The chemical compositions of the base material and the welding wire are shown in Table 1. The buttering layer weld overlay adopted the swing nonpulse hot wire gas tungsten arc welding (GTAW) process, with detailed process parameters shown in Table 2. For improving overlaying efficiency, swing nonpulse hot wire GTAW was selected, even though overlay can be done without oscillation.

The as-welded macroscopic metallographic sample was taken from the cross-section of the welded isolation layer. The sample was mechanically grounded and polished and then electrolytically etched with a $\mathrm{CrO}_{3}$ acid $10 \%$ (w/v) aqueous solution at $6 \mathrm{~V}$ etching voltage for $10 \mathrm{~s}$ to reveal their microstructure. We used the etchant solution and etching process for structural analysis and used an optical microscope (Olympus GX51) to observe the metallographic structure of the deposited metal. We used scanning electron microscope (Zeiss EVO18) to further magnify the surface microstructure and the fracture morphology of the sample. The regional composition analysis was performed using the Oxford INCA energy dispersive X-ray spectrometer.

\section{Test results and analysis}

\subsection{DMW fusion zone metallographic structure}

Figure 1 shows the macroscopic metallograph of the crosssection of DMWs. It is evident that the DMW was complete without welding defects, such as porosity or cracks, and the fusion boundary was clearly visible.

Figure 2 shows the microscopic metallographic structures of the different zones on the SA508-base-metal side of the cross-section of DMW. Figure 2a shows that the structure in the coarse grain heat-affected zone (CGHAZ) was bainite. Figure $2 \mathrm{~b}$ shows the structure in the fine grain heat-affected zone (FGHAZ) was bainite with uniform fine equiaxed grains. As shown in Fig. 2c, the structure in the intercritical

Table 1 Compositions of base metal and experimental filler metal(wt. \%)

\begin{tabular}{lllllllllll}
\hline Material & $\mathrm{C}$ & $\mathrm{Si}$ & $\mathrm{Mn}$ & $\mathrm{S}$ & $\mathrm{P}$ & $\mathrm{Fe}$ & $\mathrm{Ni}$ & $\mathrm{Cr}$ & $\mathrm{Nb}+\mathrm{Ta}$ & $\mathrm{Mo}$ \\
\hline SA508 Gr.3 Cl.2 base metal & 0.18 & 0.17 & 1.4 & 0.003 & 0.005 & 96.79 & 0.51 & 0.14 & - & 0.51 \\
ERNiCrFe-13 filler metal & 0.014 & 0.15 & 0.74 & 0.001 & 0.001 & 8.3 & $\mathrm{Bal}$ & 29.9 & 2.6 & 3.5 \\
\hline
\end{tabular}

Table 2 GTAW buttering welding parameters

\begin{tabular}{llllllll}
\hline Polarity & $\begin{array}{l}\text { Current } \\
\text { I/A }\end{array}$ & $\begin{array}{l}\text { Voltage } \\
\mathrm{U} / \mathrm{V}\end{array}$ & $\begin{array}{l}\text { Welding speed } \\
\mathrm{v}_{1} /(\mathrm{mm} / \mathrm{min})\end{array}$ & $\begin{array}{l}\text { Feeding speed } \\
\mathrm{v}_{2} /(\mathrm{m} / \mathrm{min})\end{array}$ & $\begin{array}{l}\text { Preheated tempera- } \\
\text { ture } \\
\mathrm{T}_{1} /{ }^{\circ} \mathrm{C}\end{array}$ & $\begin{array}{l}\text { Interpass temperature } \\
\mathrm{T}_{2} /{ }^{\circ} \mathrm{C}\end{array}$ & $\begin{array}{l}\text { Swing amplitude } \\
\text { w/mm }\end{array}$ \\
\hline DCEN & $290-360$ & $10-18$ & $90-200$ & $3000-4000$ & $121-150$ & $\leq 177$ & $\begin{array}{l}\text { Shielding gas } \\
10-16\end{array}$ \\
\hline
\end{tabular}


Fig. 1 DMW macroscopic metallography

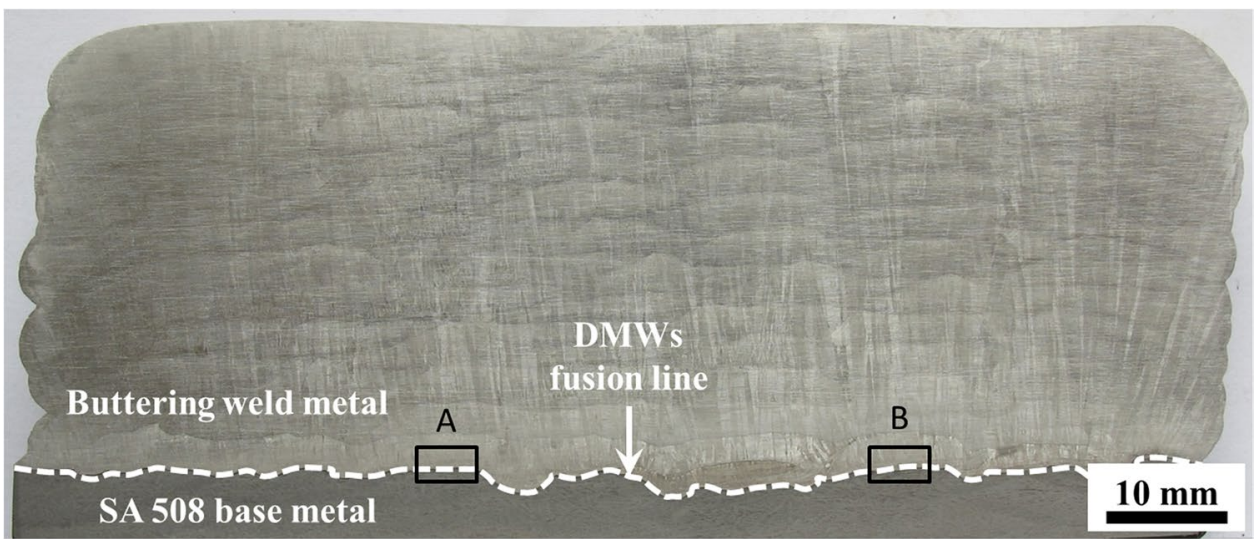

Fig. 2 The structures of different zones on the base metal side of the DMW fusion boundary: a coarse grain heat-affected zone (CGHAZ), b fine grain heat-affected zone (FGHAZ), c intercritical heat-affected zone (ICHAZ)
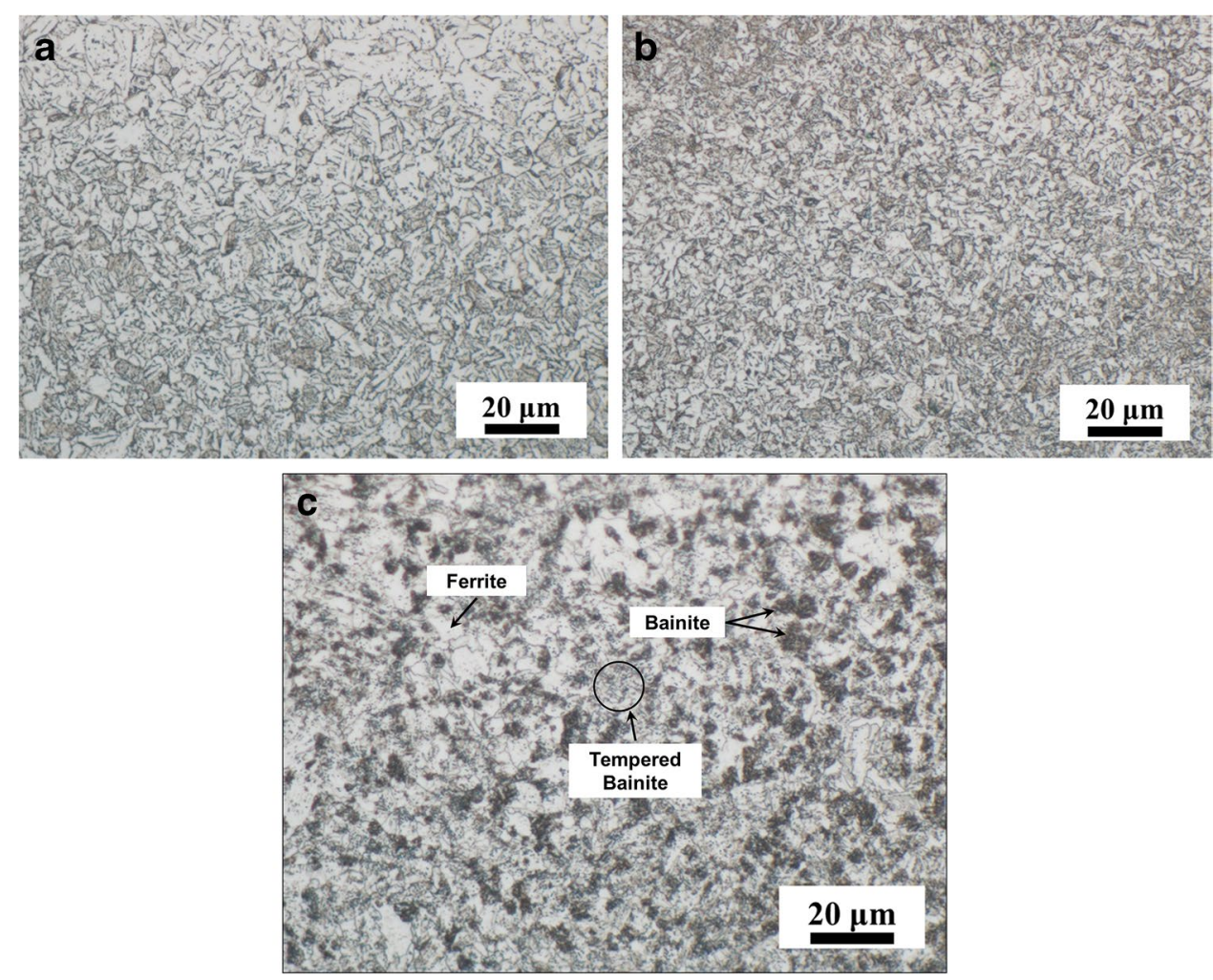

heat-affected zone (ICHAZ) was a combination of bainite, tempered bainite, and a trace amount of ferrite.

Figure 3 shows the microscopic metallographic structure of the DMW cross-section at different positions on the weld side along the fusion boundary. Figure $3 \mathrm{a} / \mathrm{b}$ was taken from sample A and Fig. 3c was taken from sample B as shown in Fig. 1; both sample A and B were taken in the center of a weld bead. Many terminologies such as beach/peninsula/ island [16], featureless zone [17], white etching region [18], and weld metal swirls [19] have been used to describe the microstructures near the fusion line in DMWs. In this paper, we named structures after their shapes including beach, peninsulas, and islands on the weld side along the fusion boundary according to naming method proposed by Kou
$[16,20,21]$, which attributed to severe macrosegregation caused by dissimilar filler metal. It has been reported that the macrosegregation in dissimilar weld joint may have a negative effect on joint property, such as stress corrosion cracking, solidification cracking, ductility reduction, and corrosion[22-25].

Figure 3a shows that the beach structure was distributed along the fusion boundary with a width of 30-50 $\mu \mathrm{m}$. Figure $3 \mathrm{~b}$ shows there were very thin $(2-4 \mu \mathrm{m})$ beach structure along fusion boundary and isolated islands structures nearby. In addition, we observed type I grain boundaries perpendicular to the fusion boundary and type II grain boundaries parallel to the fusion boundary on the weld side, but they were not continuous. In Fig. 3c, we also 
Fig. 3 The structures at different positions along the a beach structure, $\mathbf{b}$ island structures, $\mathbf{c}$ beach and island structures fusion boundary of the DMWs:
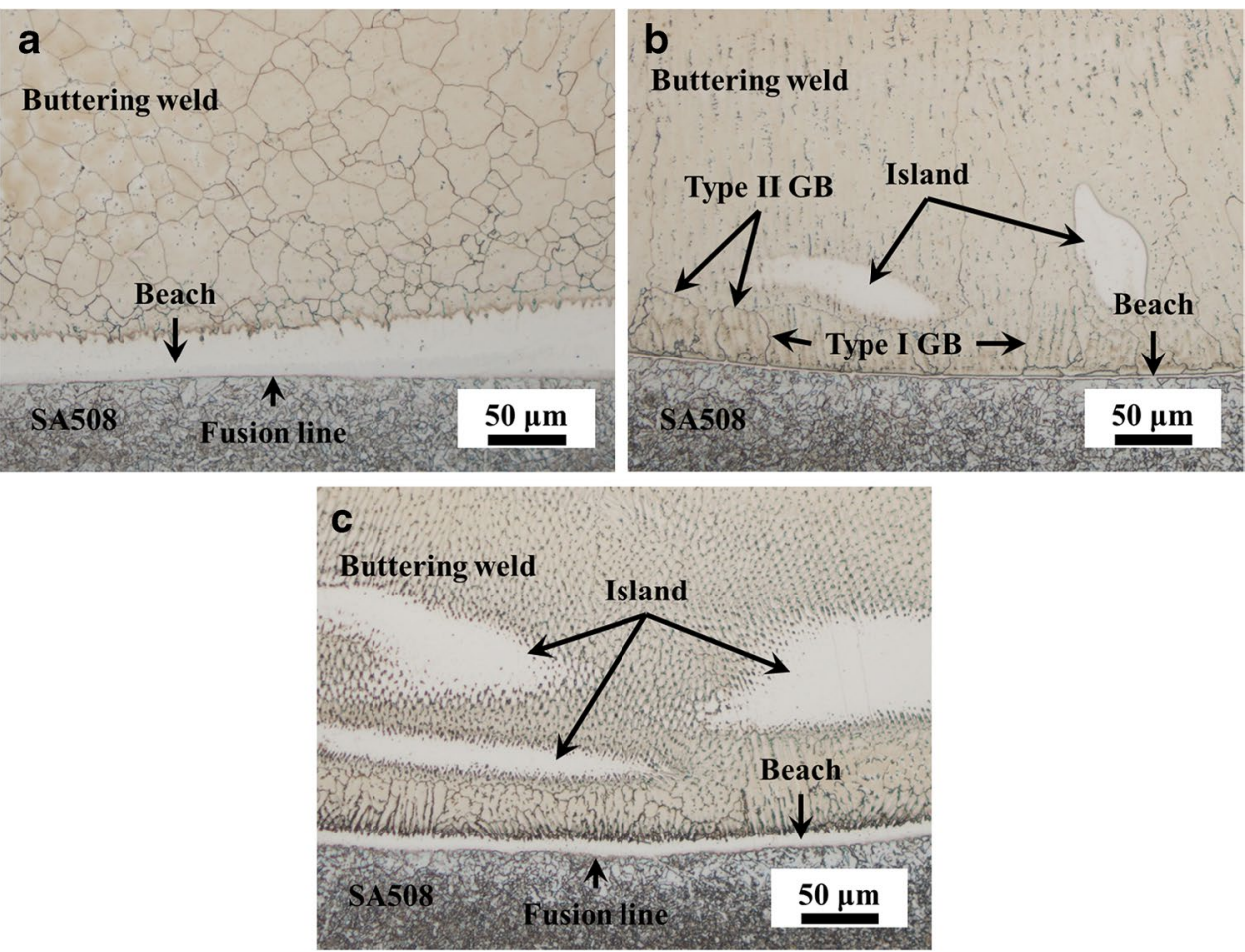

simultaneously found beach and island structures. The width of beach structure shown in Fig. 3c was approximately $15 \mu \mathrm{m}$, which was narrower than the beach in Fig. 3a and wider than the beach in Fig. 3b. Therefore, the structures were not evenly distributed along the weld side of the fusion boundary.

\subsection{Structures on the weld side of the DMW fusion boundary}

Figure 4 is a scanning electron microscope image of the structures on the weld side at different positions along the DMW fusion boundary. As shown in Fig. 4a, the beach
Fig. 4 The structures at different positions along the fusion boundary of the DMWs: a beach and peninsula structures, b beach and island structures, $\mathbf{c}$ beach structure, $\mathbf{d}$ line scan
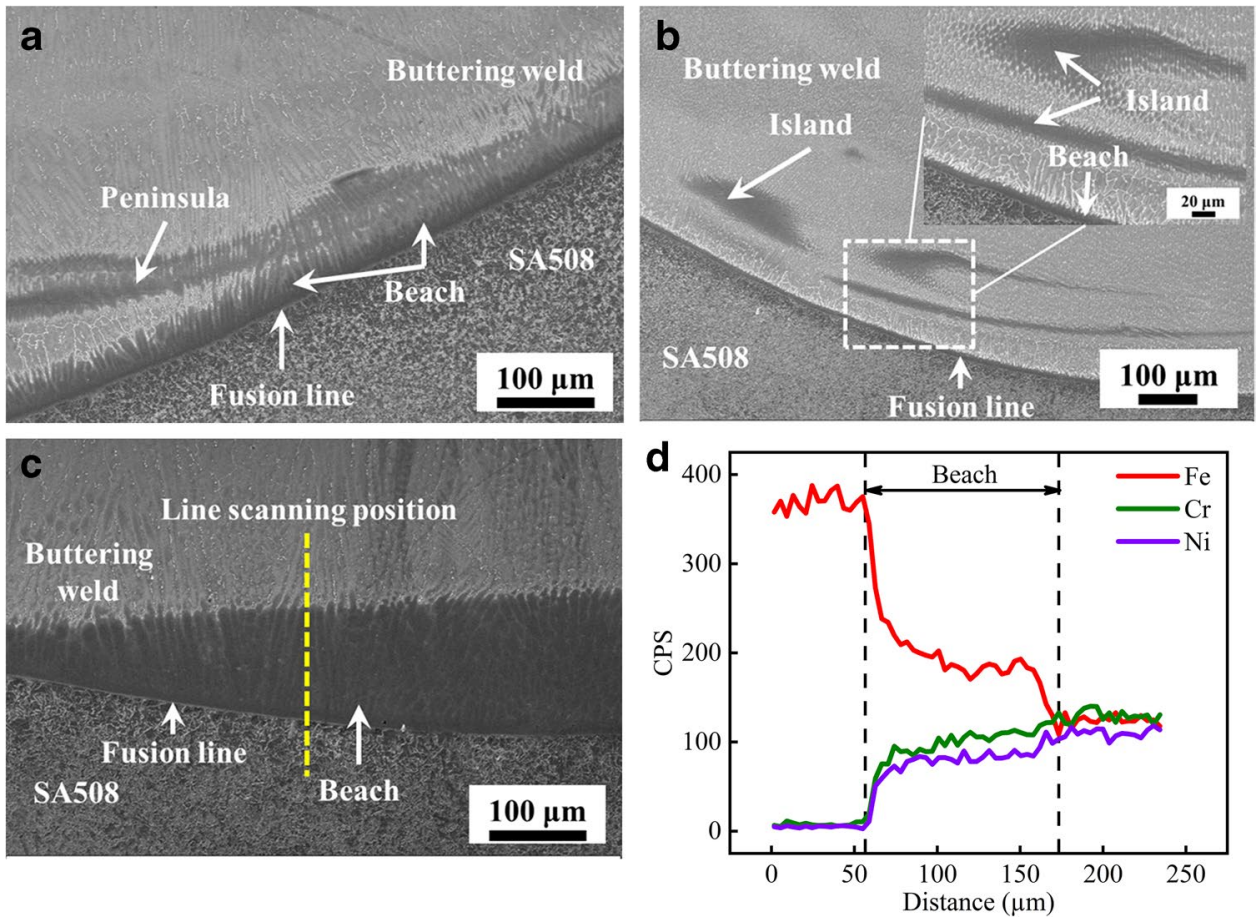
structure was distributed continuously along the fusion boundary with the width ranging between 30 and $50 \mu \mathrm{m}$. The peninsula structures were connected to the beach structure, parallel to the fusion boundary and the beach structure. Conspicuous dendritic morphology could be partially found in the beach and peninsula structures. As can be seen in Fig. $4 \mathrm{~b}$, the beach structure also was distributed continuously along the fusion boundary with a narrower width compared with Fig. 4a. The island structures were parallel to the fusion boundary and the beach structure. Figure $4 \mathrm{c}$ shows that the width of the beach structure was uneven, ranging from 50 to $150 \mu \mathrm{m}$. Combined with the line scan results shown in Fig. 4d, the composition of the beach structure was between base metal and filler metal.

Table 3 gives the energy-dispersive X-ray spectrometer values of the corresponding structures in Fig. 4. The compositions of the beach, peninsula, and island structures were slightly different, which was caused by the different degree of mixing of the molten SA508 base material and the filler metal. The iron content in the island structures was lower than that in the beach structure, whereas the nickel and chromium contents were higher, indicating more sufficient mixing. The degree of mixing in peninsula structures was between the beach structure and the peninsula structure.

Figure 5 shows the micro characteristics of the region along the fusion line of the DMWs. As seen in Fig. 5a, EBSD inverse pole figure (IPF) maps show the grain crystallographic orientation and grain size distribution of both the weld and base metal near the fusion line. The austenite grain orientations at weld side are dispersed as most neighboring grains are of largely different orientations, which also can be further quantitatively confirmed in Fig. $5 \mathrm{c}$ with
Table 3 EDS analysis results

Fig. 5 EBSD maps of DMW along fusion boundary: a inverse pole figures (IPF), $\mathbf{b}$ corresponding pole figures $(\mathrm{PF})$, frequency statistics of misorientation angle for austenite $\mathbf{c}$ in weld side and ferrite $\mathbf{d}$ in base metal side

\begin{tabular}{lllllll}
\hline Position of analysis & $\mathrm{Fe}$ & $\mathrm{Ni}$ & $\mathrm{Cr}$ & $\mathrm{Si}$ & $\mathrm{Mo}$ & $\mathrm{Mn}$ \\
\hline Beach structure & 55.51 & 26.42 & 14.32 & 0.23 & 1.66 & 0.80 \\
Peninsula structure & 48.12 & 30.26 & 16.51 & 0.15 & 2.15 & 1.03 \\
Island structure & 43.76 & 32.96 & 18.00 & 0.15 & 2.3 & 1.01 \\
\hline
\end{tabular}
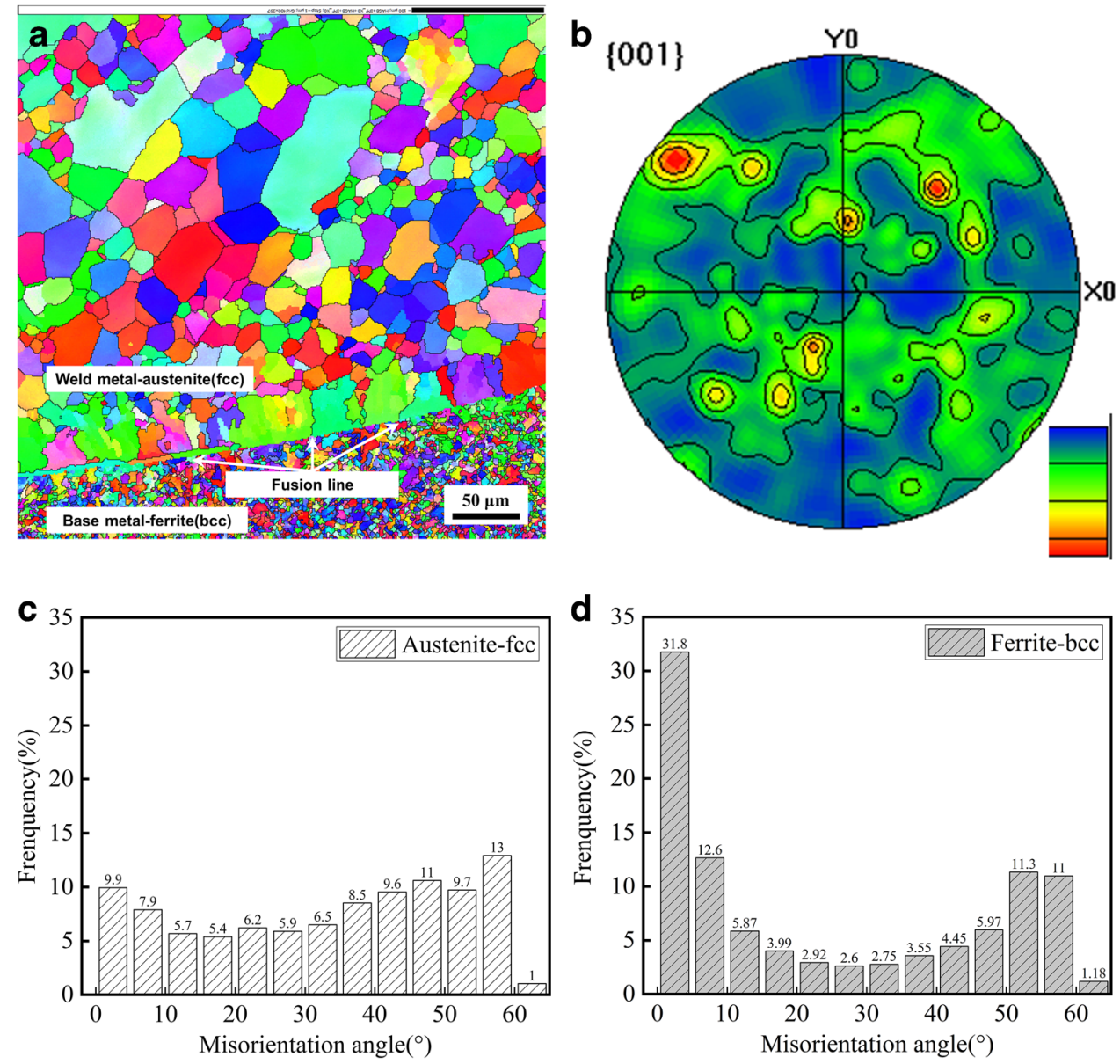
$75 \%$ large $\left(>15^{\circ}\right)$ misorientation in frequency. Figure $5 \mathrm{~b}$ indicates that the overall texture orientation deviates from the $<100>$ direction and distributes dispersedly.

\subsection{Structure formation mechanism}

When there was a significant difference in the composition of the base metal and the weld, a macro-scale segregation occurred in the weld a few hundred micrometers to 1 or $2 \mathrm{~cm}$ away from the fusion boundary of DMWs [20, 21]. Kou et al. [16] systematically explained the macrosegregation phenomenon in DMWs based on the theory of constitutional undercooling and the difference in liquidus temperatures of the base material and the weld metal.

Figure 6 shows the initial solidification temperature and the initial solidification phase at different dilution ratios calculated using the JMatPro solidification computational module and the database of steel and nickel-based alloy. When the dilution ratio was $0 \%$ and $100 \%$, the corresponding initial solidification temperatures of the compositions in base metal and filler metal in Table 1 were $1520{ }^{\circ} \mathrm{C}$ and $1360{ }^{\circ} \mathrm{C}$, respectively. It was evident that the initial solidification temperature increased significantly with the increasing dilution ratio. When the dilution ratio exceeded $94.5 \%$, the initial solidification phase transformed from the face-centered cubic $\gamma$-austenite into the body-centered cubic $\delta$-ferrite. It is worth noting that the results in Fig. 6 based on the assumption that all elements vary linearly with dilution, while for carbon, it moves away from bases metal into weld much faster than other elements. Changes in the local carbon concentration may have a massive effect on phase stability and solidification temperature ranges. Therefore, Fig. 6 mainly aimed at discussing solidification

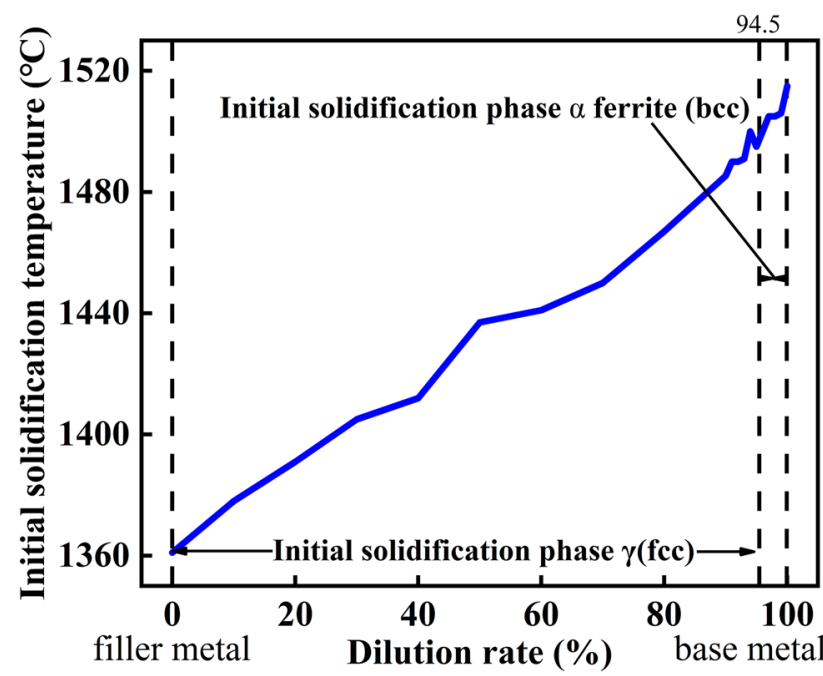

Fig. 6 The effect of dilution ratio on solidification mode, especially initial solidification phase based on the calculated results without taking the phase transformation after solidification and carbon diffusion into consideration.

During the heating process of the weld pool, the fusion boundary corresponded to the isotherm of the base material's melting point. Because of the viscosity of the liquid metal, a stagnant or laminar-flow layer of liquid metal existed at the boundary of the weld pool near the fusion boundary. This layer of liquid base material may solidify before it is fully mixed with the weld, forming a layered beach structure along the fusion boundary. Because of the unstable convection in the weld pool during the welding process, the swing process we used may have aggravated the turbulent flow in the weld pool. When this layered structure was scoured and stirred into the weld, it quickly cooled and solidified because of the constitutional undercooling, forming island structures or peninsular structures connected with the beach structure. As for islands formation mechanism, it can be seen that all islands were dendritic structure as shown in Fig. $4 a$ and b, which was significant solidification structure. The composition of island was between filler metal and base metal as shown in Table 3. Both dendritic structure and the base metallike compositions of islands indicate that they originated from the liquid base metal, instead of solid base metal that detached from the base metal substrate and swept into the molten weld pool. Similar research evidences from Kou et al. [21] also support this view.

The formation of the initial solidification phase depended on the chemical composition, which locally depended on the degree of mixing. When SA508 base material and filler metal were mixed sufficiently, the initial solidification phase was the austenite $\gamma$-phase. When the two were not sufficiently mixed, ferrite was formed when solidified with a composition close to the base material SA508. For the composition of each typical structure given in Table 3, we estimated that the dilution ratio was between 40 and $60 \%$ according to the chemical composition in Table 1, which solidified to form $\gamma$-austenite.

As a result of the turbulent flow of the weld pool, solidification in the form of ferrite also was possible in the weld near the fusion boundary. Figure 7 is EBSD distribution map of bcc and fcc phases near the DMW fusion boundary. The blue crescent structure is $\alpha$ phase, sporadically distributed in $\gamma$ phase. No epitaxial growth can be found at the interface of DMW fusion boundary because SA508 was a bcc structure, whereas weld was an fcc structure.

In this paper, we mainly focus on the DMWs microstructure and its formation mechanism; the effect of DMWs microstructure on mechanical properties and corrosion needs to be investigated in detail in the future. 


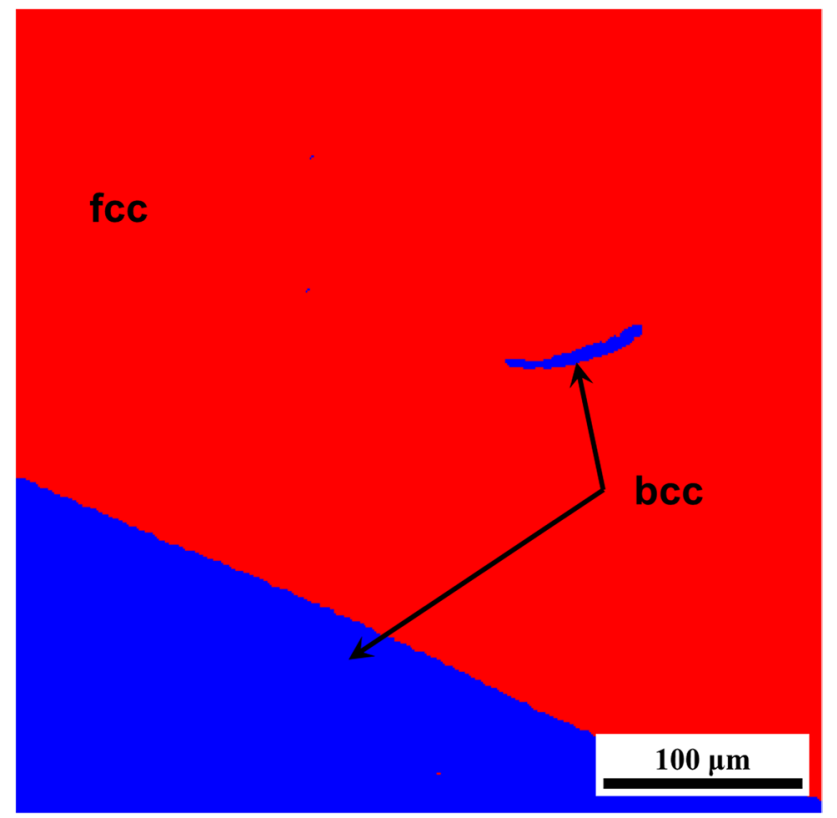

Fig. 7 Phase distribution map on both sides of the DMW fusion boundary

\section{Conclusion}

The following are the conclusions of this research:

1. DMWs were complete, without welding defects, such as porosity or cracks. We did not observe any epitaxial growth at the interface of the fusion boundary.

2. The structures of the fusion zone included the beach and the peninsula structures along the fusion boundary and the island structures in the weld. The distribution of these three types of structures near the fusion boundary was not even. The beach was formed due to the insufficient mixing and solidification of the molten liquid base material and the filler metal, with the width ranging from 0 to $150 \mu \mathrm{m}$. The peninsulas and islands were formed by the undercooling of the insufficiently mixed liquid base material and filler metal that entered the weld because of the convection and scouring of the weld pool.

3. The initial solidification temperature of the corresponding composition increased significantly with the increasing dilution ratio. When the dilution ratio exceeded $94.5 \%$, the initial solidification phase transformed from the face-centered cubic $\delta$-austenite into the body-centered cubic $\delta$-ferrite. Island structures existed in the form of solidified $\delta$-ferrite in the weld near the fusion boundary.

4. The austenite grain orientations at weld side are dispersed with $75 \%$ large $\left(>15^{\circ}\right)$ misorientation in frequency, and the overall texture orientation distributes dispersedly with deviating from the $<100>$ direction.
Open Access This article is licensed under a Creative Commons Attribution 4.0 International License, which permits use, sharing, adaptation, distribution and reproduction in any medium or format, as long as you give appropriate credit to the original author(s) and the source, provide a link to the Creative Commons licence, and indicate if changes were made. The images or other third party material in this article are included in the article's Creative Commons licence, unless indicated otherwise in a credit line to the material. If material is not included in the article's Creative Commons licence and your intended use is not permitted by statutory regulation or exceeds the permitted use, you will need to obtain permission directly from the copyright holder. To view a copy of this licence, visit http://creativecommons.org/licenses/by/4.0/.

\section{References}

1. Li KJ, Li XG, Zhang Yu et al (2020) Microstructure evolution and high temperature failure mechanism of dissimilar metal welded joints. Electric Welding Machine 50(9):17-43

2. Ou P, Sun J, Zhang ML et al (2013) Microstructure of SA508 /316L dissimilar steel welding joints. T Mater Heat Treat 34(10):132-138

3. Ming HL, Zhang ZM, Wang JQ et al (2017) Microstructure and local properties of a domestic safe-end dissimilar metal weld joint by using hot-wire GTAW. Acta Metall Sin 53(1):57-69

4. Ding J, Zhang ZM, Wang JQ et al (2015) Micro-charaterization of dissimilar metal weld joint for connecting pipe-nozzle to safe-end in generation III nuclear power plant. Acta Metall Sin 51(4):425-439

5. Zheng SX, Li YN, Shi W et al (2019) Microstructures and mechanical properties of welding joint of Q235/1Cr18Ni9Ti dissimilar steel with ultra-narrow-gap welding. Transactions of the China Welding Institution 40(8):38-43

6. Huang BS, Chen Q, Yang J et al (2019) Numerical simulation of welding residual stress and distortion in Q345/316L dissimilar steel. Transactions of the China Welding Institution 40(2):138-144

7. DuPont JN, Lippold JC, Kiser SD (2009) Welding metallurgy and weldability nickel-base alloy. Wiley, New York (ISBN 978-0-470-08714-5)

8. Dupont JN, Kusko CS (2007) Martensite formation in austenitic/ferritic dissimilar alloy welds. Weld J 86(2):51s-54s

9. DuPont JN, Banovic SW, Marder AR (2003) Microstructural evolution and weldability of dissimilar welds between a super austenitic stainless steel and nickel base alloys. Weld J 82(6): $125 \mathrm{~s}-135 \mathrm{~s}$

10. Petrzak P, Blicharski M, Dymek S et al (2015) Electron microscopy investigation of Inconel 625 weld overlay on boiler steel. Solid State Phenom 231:113-118

11. Rozmus-Górnikowska M, Cieniek L et al (2014) Microstructure and microsegregation of an Inconel 625 weld overlay produced on steel pipes by the cold metal transfer technique. Arch Metall Mater 59(3):1081-1084

12. Monika S,Pawel P, Agnieszka R et al (2015) The microstructure of weld overlay Ni-Base alloy deposited on carbon steel by CMT method. Solid State Phenom 231:119-124

13. Wheeling RA, Lippold JC (2016) Characterization of weld metal microstructure in a Ni-30Cr alloy with additions of niobium and molybdenum. Mater Charact 115(5):97-103

14. Li CH, Shao M, Fink C et al (2018) TEM investigation on eutectic phase formation in Ni-30Cr filler metal 52XL. Microsc Microanal 24(S1):42-43

15. Xiao G, Peng H, Kai X et al (2020) Microstructure and mechanical properties of deposited metal with a nickel alloy welding 
wire for nuclear plant. Transactions of the China Welding Institution 41(4):26-30

16. Yang YK, Kou S (2007) Fusion-boundary macrosegregation in dissimilar-filler metal Al-Cu welds. Weld J 86(11):331-339

17. Alexandrov BT, Lippold JC, Sowards JW et al (2013) Fusion boundary microstructure evolution associated with embrittlement of Ni-base alloy overlays applied to carbon steel. Welding in the World 57(1):39-53

18. Olden V, Kvaale PE, Simensen PA, et al (2003) The effect of PWHT on the material properties and micro structure in Inconel 625 and Inconel 725 buttered joints[C]. International Conference on Offshore Mechanics \& Arctic Engineering, Cancun, Mexico 2003-37196

19. Buntain R, Alexandrov B, Viswanathan G (2020) Characterization of the interpass microstructure in low alloy steel/Alloy 625 HW-GTAW narrow groove welds. Mater Charact 170(9):110638

20. Yang YK, Kou S (2007) Weld-bottom macro segregation caused by dissimilar filler metals. Weld J 86(12):373-387
21. Yang YK, Kou S (2010) Macrosegregation mechanisms in arc welds made with dissimilar filler metals. Sci Technol Weld Joining 15(1): 15-30

22. Doody T (1992) Intermediate mixed zones in dissimilar metal welds for sour service. Weld J 71(3):55-60

23 Chen S, Huang J, Xia J et al (2015) Influence of processing parameters on the characteristics of stainless steel/copper laser welding. J Mater Process Technol 222:43-51

24. Xu H, Xu MJ, Yu C et al (2017) Effect of the microstructure in unmixed zone on corrosion behavior of 439 tube/308L tube-sheet welding joint. J Mater Process Technol 240:162-167

25. Barr C, Da Sun S, Easton $M$ et al (2018) Influence of macrosegregation on solidification cracking in laser clad ultra-high strength steels. Surf Coat Technol 340:126-136

Publisher's note Springer Nature remains neutral with regard to jurisdictional claims in published maps and institutional affiliations. 